\title{
Filament activated chemical vapor deposition of boron carbide coatings
}

\author{
Sadanand V. Deshpande and Erdogan Gulari \\ Department of Chemical Engineering, University of Michigan, Ann Arbor, Michigan 48109 \\ Stephen J. Harris and Anita M. Weiner \\ Physical Chemistry, General Motors Research \& Development Center, Warren, Michigan 48090-9055
}

(Received 10 May 1994; accepted for publication 25 July 1994)

\begin{abstract}
In this study, we have demonstrated that boron carbide, an extremely hard and wear-resistant material, can be deposited with hot filament-activated chemical vapor deposition (HFCVD). There are several benefits to using a hot filament system, including a high deposition rate and a relatively low substrate temperature with a process that is not line-of-sight. High purity, apparently amorphous boron carbide films were obtained by the use of a chlorine based precursor (which is less toxic than diborane). This indicates that either the hot filament helps in complete decomposition of $\mathrm{BCl}_{3}$ or the presence of high concentration of atomic hydrogen in a HFCVD environment helps in scavenging the chlorine. (C) 1994 American Institute of Physics.
\end{abstract}

Hot filament chemical vapor deposition (HFCVD) has been studied extensively in the last decade for deposition of polycrystalline diamond films. ${ }^{1-5}$ It is an attractive technique due to its simple design and its amenability to fundamental chemical kinetic modeling in understanding the process chemistry. HFCVD has also been used to deposit thin films of amorphous/polycrystalline silicon and a variety of nitrides. $^{6-11}$

In this letter we report the first use of HFCVD for lowtemperature deposition of amorphous boron carbide thin films. In this method, thermal/catalytic cracking of the precursors occurs at the hot filament, which helps in achieving a lower deposition temperature. We have deposited boron carbide films utilizing methane and boron trichloride as precursors with hydrogen as the carrier gas. These films have been characterized by Fourier-transform infrared absorption (FTIR), x-ray photoelectron spectroscopy (XPS), x-ray diffraction, adhesion testing, and scanning electron microscopy.

An excellent review of properties and uses of boron carbide is presented in Ref. 12. Boron carbide is among the hardest and most abrasion-resistent materials. Crystalline boron carbide has a complex structure that is composed of icosahedral (with 12 atoms at vertices of a regular polyhedron with 20 faces) clusters linked by three-atom chains into a rhombohedral lattice. It has a wide range of phase homogeneity ( 8.8 to 20 at. \% carbon) because of the interchangeability of boron and carbon atoms in the crystal structure. In addition, boron carbide has a high melting point, low density, and great resistance to chemical reagents. Therefore, boron carbide $\left(\mathrm{BC}_{x}\right)$ thin films are good candidates for hard and wear-resistant tribological coatings. Although a few plasmabased chemical vapor deposition studies at low substrate temperature have been reported, ${ }^{13-15}$ commercial thin films of boron carbide are either deposited at very high temperatures $\left(900-1200{ }^{\circ} \mathrm{C}\right)$ or with a line-of-sight sputtering technique. High deposition temperatures are not acceptable for heat-treated ferrous-based metals or other heat sensitive materials, and it can be difficult and costly to use a line-of-sight technique for some parts with complex shapes.

Our reactor consists of a stainless-steel six-way cross with translation stages for both the substrate heater and the filament assembly, two glass view ports, a gas feed, and a pumping port. Reactant gases were fed into the chamber through mass flow controllers and decomposed at a resistively heated tungsten filament maintained at $2100{ }^{\circ} \mathrm{C}$, as measured by an optical pyrometer. The deposition conditions are summarized in Table I. They indicate a residence time on the order of half a minute. The filament was carburized for about $1.5 \mathrm{~h}$ in a methane-hydrogen mixture before the addition of boron trichloride in order to insure as much as possible that the filament did not change during the growth. In order to improve the uniformity over the substrate, the filament was made from two straight elements of equal lengths $(\sim 5.0 \mathrm{~cm}$ each). The $p$-type silicon (100) substrates (resistivity $=4-8 \Omega \mathrm{cm}$ ) were supported on a tantalum sheet about $10 \mathrm{~mm}$ from the filament. Silicon was used as a substrate in these preliminary experiments because it is transparent in the midinfrared region, which allows us to examine bonding configurations in the films with infrared spectroscopy. The substrates were heated primarily by the radiation from the filament and by $\mathrm{H}$ atom recombination on its surface. $^{16}$ The substrate temperature was estimated with a $\mathrm{Pt}-\mathrm{Pt} / \mathrm{Rh}$ thermocouple that was spot welded to the tantalum sheet, which rested on a 1-in.-diam molybdenum block heater.

The deposition rates were determined from crosssectional scanning electron micrographs (SEM). The bonding configurations in the films were identified by transmission infrared spectroscopy. The film compositional depth profile was obtained with a Perkin Elmer x-ray photoelectron spectrometer equipped with a $3.0-\mathrm{keV} \mathrm{Ar}^{+}$ion gun. The el-

TABLE I. Deposition parameters for $a-\mathrm{BC}_{x}: \mathrm{H}$ thin films.

\begin{tabular}{lc}
\hline \hline \multicolumn{1}{c}{ Parameter } & Set point(s) \\
\hline Reactor pressure & 6.0 Torr \\
Substrate temperature & $450^{\circ} \mathrm{C}\left( \pm 15^{\circ} \mathrm{C}\right)$ \\
Filament temperature & $2100^{\circ} \mathrm{C}$ \\
Gas flow rates: & \\
Hydrogen & $84.0 \mathrm{sccm}$ \\
Methane & $1.6 \mathrm{sccm}$ \\
Boron trichloride & $4.0-8.0 \mathrm{sccm}$ \\
\hline \hline
\end{tabular}




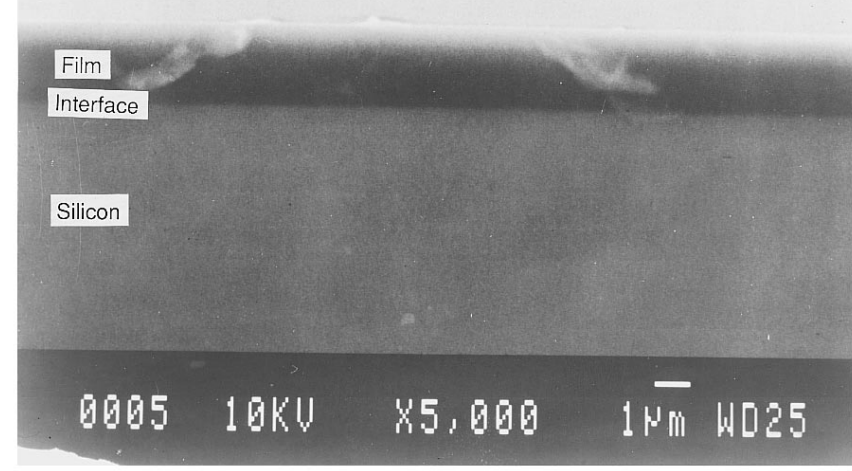

FIG. 1. Cross-sectional SEM of a boron carbide film on silicon.

emental sensitivity factors provided for the spectrometer were used to determine the film composition without any further correction (or the use of a standard). X-ray diffraction measurements were taken on a thick film $(\sim 3.0 \mu \mathrm{m})$ deposited on silicon. The film adhesion and wear resistance on silicon substrates were studied with a standard pin-on-disk apparatus.

The average deposition rate was about $4.5 \mu \mathrm{m} / \mathrm{h}$ for $\mathrm{BCl}_{3}$ flow rate of $4.0 \mathrm{sccm}$ and a substrate temperature of $450{ }^{\circ} \mathrm{C}$. There did not appear to be any significant induction time for film growth, as is normally observed in diamond CVD on unpolished silicon wafers. ${ }^{3,5}$ The film surface was very smooth as seen by the SEM. Figure 1 shows a crosssectional view of a boron carbide film. No grain structure is seen in the film which, together with our inability to detect any x-ray scattering, suggest that the films were amorphous.

A typical FTIR spectrum of a boron carbide film deposited on silicon is shown in Fig. 2. The broad peak centered at $1170 \mathrm{~cm}^{-1}$ is assigned to $\mathrm{B}-\mathrm{C}$ bonds in the film. The pres-

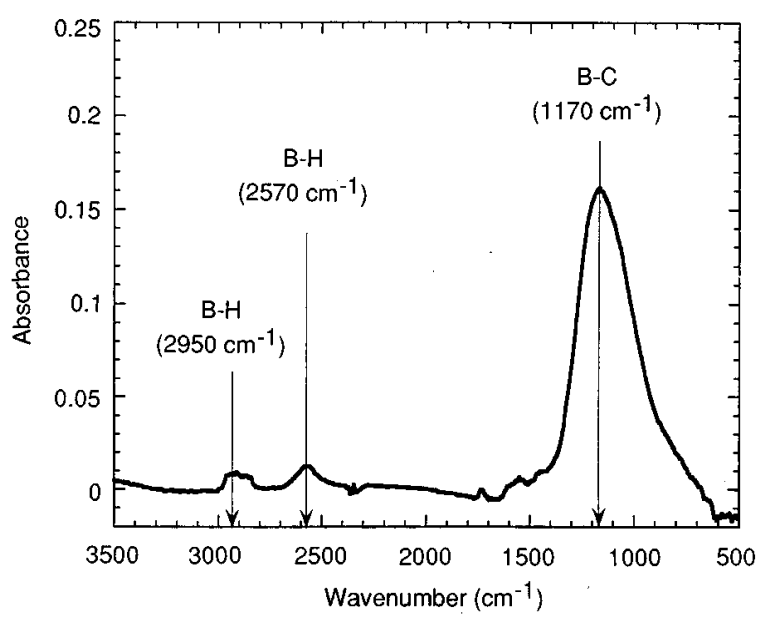

FIG. 2. FTIR spectrum of $a-\mathrm{BC}_{x}: \mathrm{H}$ film deposited on silicon. ence of hydrogen in or on the surface of the films can be observed from the $\mathrm{B}-\mathrm{H}$ and $\mathrm{C}-\mathrm{H}$ stretching regions at 2570 and $2950 \mathrm{~cm}^{-1}$, respectively. It may also be noted that $\mathrm{B}-\mathrm{H}-\mathrm{B}$ bridge bonds in the region $1600-2000 \mathrm{~cm}^{-1}$ are not seen in these films, as was reported elsewhere. ${ }^{14,17}$ This indicates that the hydrogen is primarily bonded terminally to boron in an amorphous B-C network.

A compositional depth profile of the films was obtained by XPS with the use of an Ar ion gun. The boron to carbon ratio in the film bulk was determined to be nearly 3.0. Crystalline boron carbide with this ratio would not exist in a single phase, but would be a mixture of $\mathrm{B}_{4} \mathrm{C}$ and graphite. ${ }^{12}$ If our films are amorphous, however, there need be no separate graphite phase present. The $\mathrm{B} / \mathrm{C}$ ratio did not change measurably upon varying the $\mathrm{BCl}_{3}$ flow rate between 4.0 and $8.0 \mathrm{sccm}$, corresponding to $\mathrm{B} / \mathrm{C}$ ratios of 2.5 to 5.0 in the gas phase. A small amount of oxygen (6 at. \%) was detected on the surface of these films, but the film bulk did not have any measurable amounts of oxygen. Also, no measurable amount of chlorine was detected in the films, in spite of $\mathrm{BCl}_{3}$ being the boron source. This was an unexpected result since Cholet et al. ${ }^{15}$ have shown that significant amounts of halogen
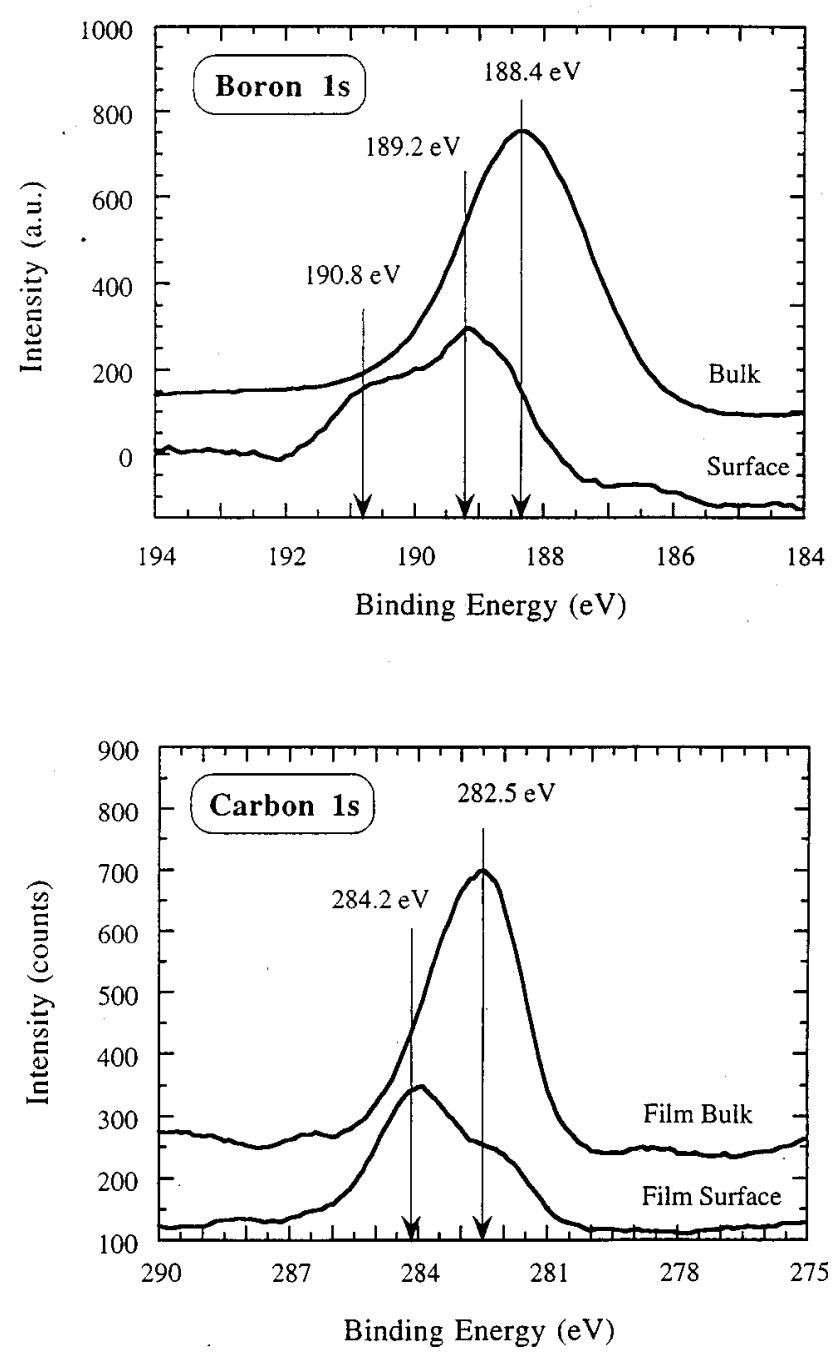

FIG. 3. Boron 1-s peak and carbon 1-s peak from XPS spectra. 
(2\%-5\% bromine) are incorporated in the films at low substrate temperatures $\left(400-500{ }^{\circ} \mathrm{C}\right)$. Furthermore, it is interesting to note that chlorine attacks boron carbide above $600{ }^{\circ} \mathrm{C} .{ }^{12}$ Consequently, at a higher deposition temperature than used in this study, there could be a competition between deposition and etching of boron carbide.

The elemental peak positions for boron and carbon are shown in Fig. 3. The boron peak on the surface has a 190.8-eV component corresponding to the surface oxide and a 189.2-eV peak representing the carbide phase. The boron 1 -s peak shifts to $188.4 \mathrm{eV}$ in the bulk of the film (after 12.0 min sputtering, when no oxygen is detectable) corresponding to a boron carbide $\left(\mathrm{BC}_{x}\right)$ phase. These peak positions match closely with the values reported in the literature for a boron carbide phase. ${ }^{13,14}$ The carbon peak on the film surface (i.e., before any sputter cleaning) had a significant 284.2-eV component due to adventitious carbon. This adventitious carbon was used as a reference for determining the boron and carbon peak positions in the film bulk. As shown in Fig. 2, the carbon 1-s peak shifts to $282.5 \mathrm{eV}$ representing a carbide in the bulk of the film.

These boron carbide films showed good adhesion to silicon substrates as determined by a tape test. In addition, adhesion and wear resistance (dry wear) of these films was studied with a pin-on-disk tribometer. A tungsten-carbide/ cobalt ball (diameter $4.0 \mathrm{~mm}$ ) was used as the pin. Low coefficients of friction, between 0.25 and 0.4 , were measured for contact (Hertzian) pressures of 314.4 and $396.1 \mathrm{MPa}$. These tests were performed for up to $15.0 \mathrm{~h}$ and no signifi- cant wear of the films was observed. This indicates that HFCVD has potential to be used as a simple deposition scheme to study tribological properties of boron carbide coatings.

We have enjoyed and appreciate many interesting and valuable discussions about boron carbide with Dr. Gary Doll of the GMR\&D Physics Department.

${ }^{1}$ S. J. Harris, Appl. Phys. Lett. 56, 2298 (1990).

${ }^{2}$ S. J. Harris and A. M. Weiner, J. Appl. Phys. 67, 6520 (1990)

${ }^{3}$ J. C. Angus and C. C. Hayman, Science 241, 913 (1988).

${ }^{4}$ C. Wolden, S. Mitra, and K. K. Gleason, J. Appl. Phys. 72, 3750 (1992).

${ }^{5}$ B. V. Spitsyn, L. L. Bouilov, and B. V. Deriyaguin, J. Cryst. Growth 52, 219 (1981).

${ }^{6}$ S. V. Deshpande, J. L. Dupuie, and E. Gulari, Appl. Phys. Lett. 61, 1420 (1992).

${ }^{7}$ J. L. Dupuie and E. Gulari, Appl. Phys. Lett. 59, 549 (1991).

${ }^{8}$ R. R. Rye, J. Vac. Sci. Technol. A 9, 1099 (1991).

${ }^{9}$ J. Sumakeris, Z. Sitar, K. S. Ailey-Trent, K. L. More, and R. F. Davis, Thin Solid Films 225, 244 (1993).

${ }^{10}$ A. H. Mahan, J. Carapella, B. P. Nelson, R. S. Crandall, and I. Balberg, J. Appl. Phys. 69, 6728 (1991).

${ }^{11}$ C. Horbach, W. Beyer, and H. Wagner, J. Non-Cryst. Solids 137\&138, 661 (1991).

${ }^{12}$ F. Thevenot, J. European Ceram. Soc. 6, 205 (1990).

${ }^{13}$ H. Kunzli, P. Gantenbein, R. Steiner, and P. Oelhafen, Fresenius Z. Anal. Chem. 346, 41 (1993).

${ }^{14}$ J. I. Onate, A. Garcia, V. Bellido, and J. L. Viviente, Surf. Coat. Technol. 49, 548 (1991).

${ }^{15}$ V. Cholet, R. Herbin, and L. Vandenbulke, Thin Solid Films 188, 143 (1990).

${ }^{16}$ S. J. Harris and A. M. Weiner, J. Appl. Phys. 74, 1022 (1993).

${ }^{17}$ W. J. Lehmann and I. Shapiro, Spectrochim. Acta 17, 396 (1961). 